\title{
FAULT LOCATION ON A DISTRIBUTION FEEDER USING FAULT GENERATED HIGH FREQUENCY CURRENT SIGNATURES
}

\author{
Hashim Hizam* \\ Department of Electrical and Electronic Engineering, Faculty of Engineering, \\ Universiti Putra Malaysia, 43400, UPM Serdang, Selangor, Malaysia

\section{P.A. Crossley} \\ School of Electrical and Electronic Engineering, Queen's University Belfast, \\ Ashby Building, Stranmillis Road, Belfast BT9 5AH, Northern Ireland
}

Received 14 August 2006

\begin{abstract}
This paper describes how the fault generated travelling waves detected in the current signals at a single location on a distribution feeder can be used for fault location. The method identifies the fault section and the probable location of the fault by comparing the relative distance of each "peak" in the high frequency current signals to the known reflection points in the distribution feeder. The probable fault location is then used within a transient power system simulator that models the actual network. The resulting simulated current waveforms are then cross-correlated against the original signal. If the estimated fault location is correct, the high frequency signatures in the simulated waveform will be similar to those of the measured waveforms and the cross-correlation value will be a high positive value. If the signatures differ, the crosscorrelation value will be negative or small. The simulation and correlation process is repeated with the next "most likely" fault location until a high degree of correlation is obtained. Simulation studies using PSCAD/EMTDC and analysis using cross-correlation suggest that this method can accurately locate a fault on a distribution feeder using measurements at a single location.
\end{abstract}

Keywords: Fault location, Travelling waves, Cross-correlation, Distribution

\section{INTRODUCTION}

One of the main objectives of an electricity provider is to ensure reliable and continuous supply to its customers. If a fault occurs on power systems, protection schemes are expected to operate and clear the fault by opening the circuit breakers and disconnect the faulted line. If the fault is successfully cleared, an auto recloser scheme is used to restore the line. However, if the reclosing attempts are not successful, the circuit breaker will remain open and the fault can be categorised as a permanent fault [1]. Under this condition it is necessary to send a repair crew to the point of fault, repair the damage and restore the line back into operation. For efficient

\footnotetext{
* Corresponding author e-mail: hashim@eng.upm.edu.my
} 
despatch of the repair crew, it is essential that the fault location can be determined accurately and rapidly.

High fault location accuracy will help speed up the repair process as the repair crew will only need to inspect a short section of the faulted line. Fast restoration of the affected line will certainly benefit both the service provider and the customers.

Fault detection and location based on the fault induced current or voltage travelling waves has been studied for many years [2 - 10]. In all these techniques, the location of the fault is determined using the high frequency transients instead of the steady state components. The main idea behind these techniques is based on the reverberation of the fault generated travelling waves in the faulty system. With GPS technology, the travelling waves based technique can provide a fault location accuracy of a few hundred metres [11].

Fault location based on the travelling waves can generally be categorised into two techniques, single-ended and double-ended. For single-ended, the current or voltage signals are measured at one end of the line and fault location relies on the analysis of these signals to detect the reflections that occur between the measuring point and the fault. For the double-ended method, the time of arrival of the first fault generated signals are measured at both ends of the lines using synchronised timers. The double-ended method does not require multiple reflections of the signals. However, single-ended location is preferred as it only requires one unit per line and a communication link is not necessary. Thus for distribution systems, if this method can be shown to be reliable, it should be less expensive and therefore preferable.

\section{TRAVELLING WAVES FAULT LOCATION: THEORY AND PRINCIPLE}

Travelling waves on power systems can be caused by many factors such as faults, lightning and switching activities. On overhead lines the waves travel at a speed close to the speed of light i.e $300000 \mathrm{~km} / \mathrm{s}$ and are detected as a voltage and a current wave.

The voltage and current on a loss-less uniform power line are related by the telegraphy equations [12].

$$
\begin{gathered}
\frac{\partial v(x, t)}{\partial x}=-L \frac{\partial i(x, t)}{\partial t} \\
\frac{\partial i(x, t)}{\partial x}=-C \frac{\partial v(x, t)}{\partial t}
\end{gathered}
$$

$\mathrm{C}$ and $\mathrm{L}$ are the capacitance and inductance of the lines per metre whereas $v(x, t)$ and $i(x, t)$ are the voltage and current changes at location $\mathrm{x}$ at time $\mathrm{t}$ due to the travelling wave. The solutions to the equations are:

$$
\begin{array}{r}
v(x, t)=f_{1}(t-x / c)+f_{2}(t+x / c) \\
i(x, t)=\frac{1}{Z_{0}} f_{1}(t-x / c)-\frac{1}{Z_{0}} f_{2}(t+x / c)
\end{array}
$$

where $c$ is velocity of the wave propagation and $Z_{0}\left(Z_{0}=\sqrt{L / C}\right)$ is the characteristic impedance of the lines. The functions $f_{1}$ and $f_{2}$ are arbitrary functions which represent two waves which travel in opposite directions.

When a fault occurs on a power line, the voltage and current will experience a sudden change in value. This abrupt change will initiate a wave which propagates away from the fault towards both ends of the line. At a discontinuity such as a busbar, a junction, a short circuit or an open 192 
circuit, this wave will be both reflected and transmitted. This wave will then continue to be reflected and transmitted until it dies out due to attenuation.

The basic principle of most single-ended travelling wave fault locators is to evaluate the fault location using the time interval between the arrival of an incident travelling wave generated by a fault and the corresponding wave reflected from the fault point $[2,4,6]$. However, since travelling waves can also be reflected by other discontinuities, identification of the desired signal is of crucial importance to the accuracy of the location decision. The most widely used analysis method is based on cross-correlation; the incident travelling wave is taken as a reference and the signal that contains the subsequent backward travelling waves is crosscorrelated with the reference. The basic idea is that the desired backward travelling waves has the same shape as the reference and generates a peak in the correlation output.

Existing travelling wave based fault locators have been applied mostly to transmission lines rather than on distribution lines. This is because distribution lines are comparatively short in length and hence it is difficult to detect separately the arrival of a fault generated incident wave and the arrival of the subsequent backward travelling waves. Moreover, a distribution line generally contains many branches which would cause multiple reflections and reduce the magnitude of the travelling waves as they propagate along the line. These branches complicate the process of identifying the desired signal.

A Bewley Lattice diagram shown in Fig. 1 can be used to describe the reverberation of a travelling wave in a power system.

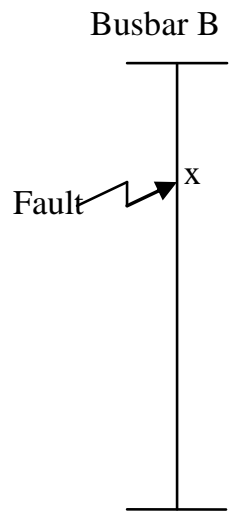

Busbar A $\begin{array}{lll}\text { B1 } & \text { B2 }\end{array}$

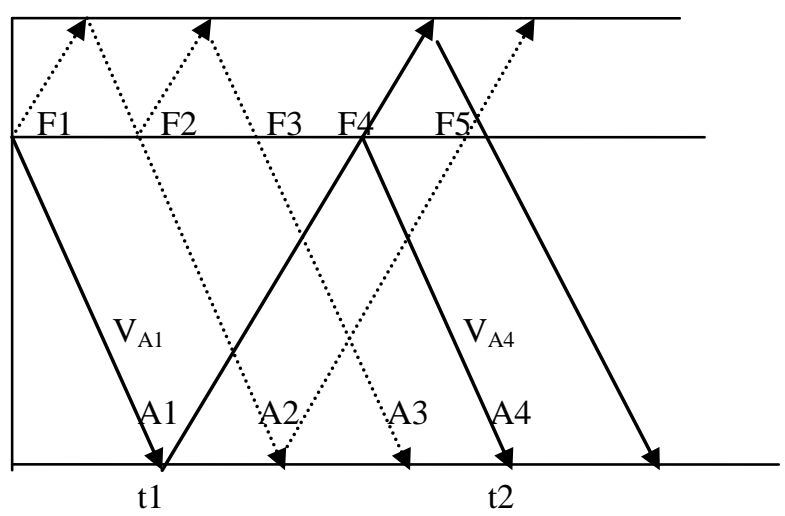

Fig. 1: Bewley Lattice diagram.

From Fig. 1, if the time interval between the arrival of the incident wave at A1 and that of the reflected wave at A4 is obtained, the distance to the fault from A can be calculated as:

$$
d=v t / 2
$$

where $v$ is the travelling wave velocity and $t$ is the time interval $(t=t 2-t 1)$.

\section{POWER SYSTEM MODELLING}

A 33/11 kV distribution was modelled using PSCAD/EMTDC. A single line diagram of the distribution feeder is shown in Fig. 2. 


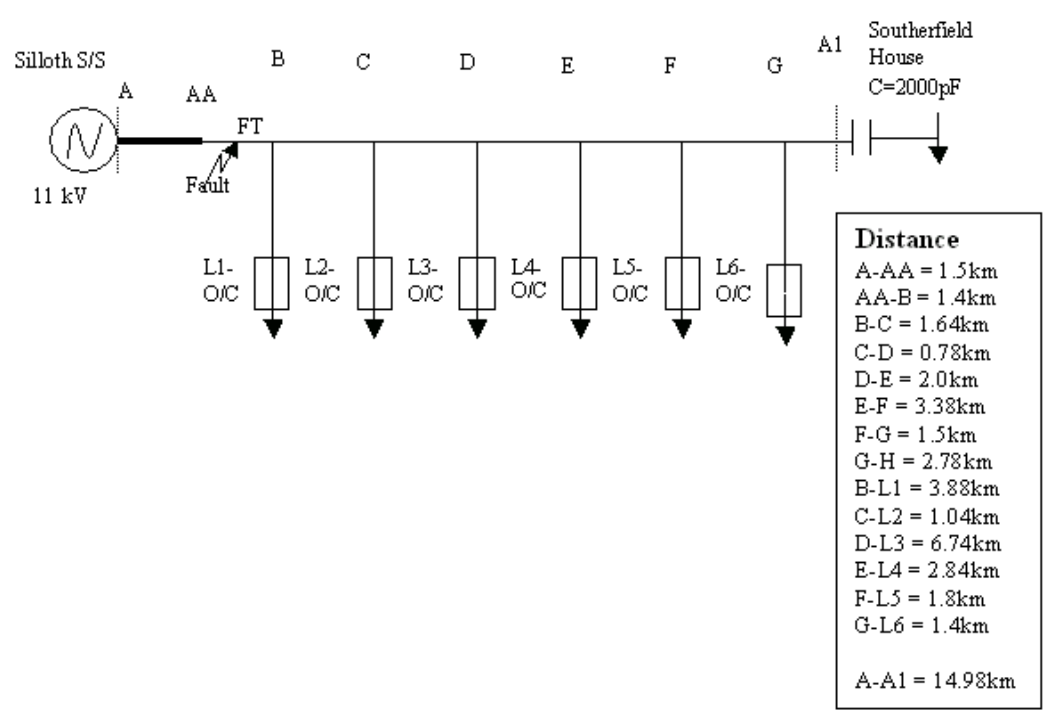

Fig. 2: Single line diagram of the distribution network.

The network consists of a short section of underground cable (section A-AA) supplying an overhead line. The total distance of the main feeder (A-A1) is $14.98 \mathrm{~km}$ and the cable section is $1.5 \mathrm{~km}$. The conductor parameters for the overhead lines were selected as follow:

- $\quad$ Number of conductors: 3

- Conductor radius: $0.005025 \mathrm{~m}$

- Conductor DC resistance: $0.5426 \mathrm{ohm} / \mathrm{km}$

- Height of conductors above the ground: $6 \mathrm{~m}$

- Horizontal spacing between phases: $0.8 \mathrm{~m}$

- Ground wires: none

- Ground resistivity: 100 ohm.m

The characteristic impedance of the overhead line is $348 \Omega$ and the velocity of the travelling wave is almost $3 \times 10^{5} \mathrm{~km} / \mathrm{s}$, i.e. the speed of light.

The parameters for the cable result in a characteristic impedance of $39.7 \Omega$ and a propagation velocity of $1.66 \times 10^{5} \mathrm{~km} / \mathrm{s}$, i.e. about $55.2 \%$ of the travelling wave velocity in free space.

A Phase A to earth fault was simulated at various points along the main feeder and the current measurement was taken at point A. The fault resistance is $0.01 \Omega$ and the time step for the simulation is $0.8 \mu \mathrm{s}$.

\section{SIMULATION RESULTS}

Figure 3 shows the high frequency current waveforms when Phase A to earth fault was simulated at a distance $1 \mathrm{~km}$ from the measurement point $\mathrm{A}$ (the fault is inside the cable section). 


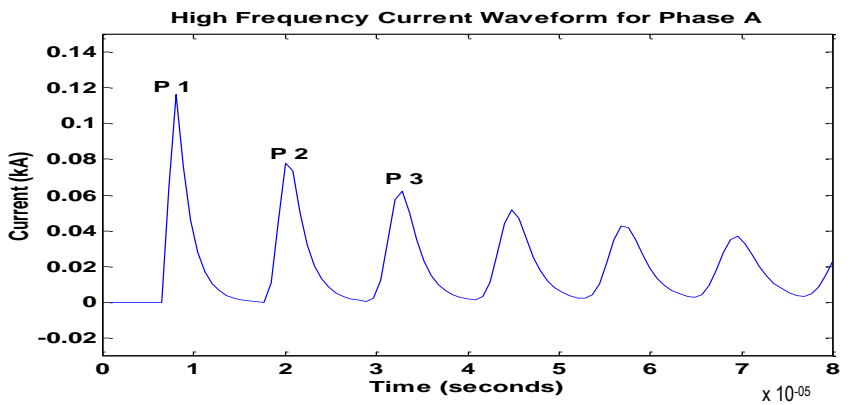

(a)

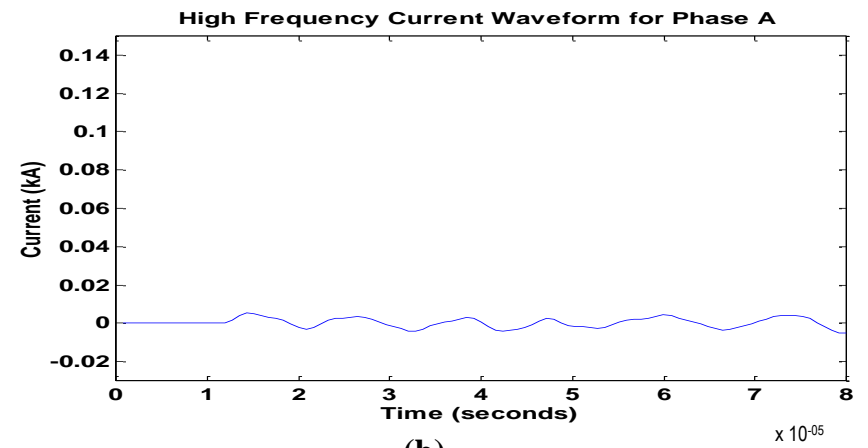

(b)

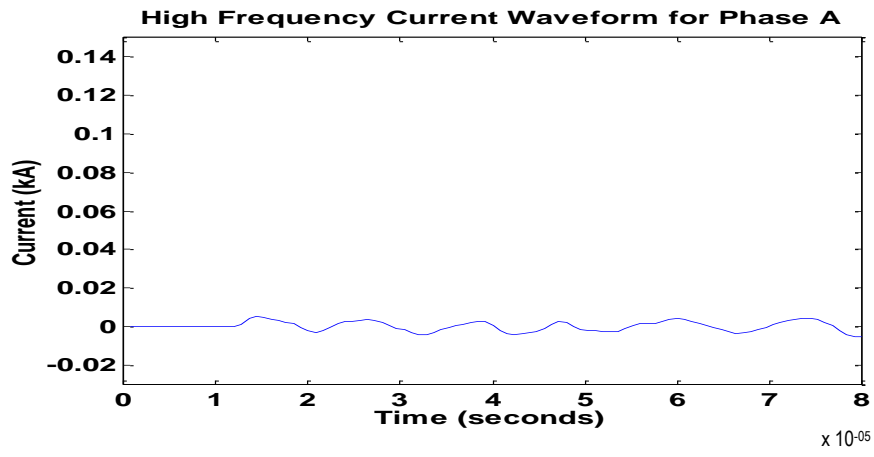

(c)

Fig. 3: Current waveforms for a fault at a distance of $1 \mathrm{~km}$. (a) phase $A,(b)$ phase $B,(c)$ phase $C$.

Comparing the magnitudes of all three phase currents reveals that the magnitude of the phase A current is significantly larger. Therefore it is concluded that the fault is a phase A to earth. Having determined the type of fault, the analysis can be done based on the faulted phase waveform. Since the fault occurred in the cable section where there is no impedance transition between the fault and the measurement point, the fault surge reverberates between these two points. Consequently the waveform is nicely defined and repetitive.

The phase A waveform shows that the highest peak occurs immediately after the fault occurred. The time delay between the start of P1 and the time that the fault occurred is $6.4 \mu$ s. Multiplying this time difference by the velocity of the travelling wave in free space $\left(3 \times 10^{5} \mathrm{~km} / \mathrm{s}\right)$, the distance travelled is $1.92 \mathrm{~km}$. This first peak is the first incident fault surge. The distance calculated, however does not reflect the actual distance from the fault point to the measurement 
point $\mathrm{A}$ (which is $1 \mathrm{~km}$ ) since the propagation velocity in free space is used instead of that in the cable. For the type of network under investigation where there is a mixture of cable and overhead line, the velocity of the travelling wave will be different in the cable section and on overhead line. This makes analysis very difficult. In order to simplify the problem, the propagation speed on the overhead line is used. Therefore for correct analysis, the effective length of the cable section has to be calculated. In this case, the effective length of the cable section is $2.71 \mathrm{~km}$ instead of the actual length of $1.5 \mathrm{~km}$ (effective length $=1.5 \mathrm{~km} \times 3.0 \times 10^{5}$ $\left./ 1.66 \times 10^{5}=2.71 \mathrm{~km}\right)$. The effective fault distance to point $\mathrm{A}$ is then calculated to be $1.81 \mathrm{~km}$. The start of P2 occurs after a time delay of $17.6 \mu \mathrm{s}$, which corresponds to a total distance travelled of $5.28 \mathrm{~km}$. The second peak is apparently the reflected wave from the fault point as the distance travelled is about three times the distance from the fault point to point A. As for P3, the time delay measured is $29.6 \mu$ s and the calculated distance travelled is $8.88 \mathrm{~km}$. This distance represents about five times the distance from the fault point to point $\mathrm{A}$ and it is the surge that is reflected from the fault point for the second time. In practice, the exact time at which the fault occurs is not known and therefore the first incident surge (P1) is used as a reference and the time difference between the first surge and subsequent surges can be used to determine the corresponding distances. Table 1 tabulates the time delay of the peaks with respect to P1; and using equation (5), the corresponding distances were calculated.

Table 1: Calculated distance of each peak relative to P1 for fault at $1 \mathrm{~km}$.

\begin{tabular}{ccc}
\hline Peak & Time Delay $(\mu$ seconds $)$ & Distance $(\mathbf{k m})$ \\
\hline P1 & 0.0 & 0 \\
P2 & 12.0 & 1.8 \\
P3 & 24.8 & 3.72 \\
P4 & 36.8 & 5.52 \\
\hline
\end{tabular}

Since the fault occurs at a point where there is no branch between point A and AA, the fault surge will travel back and forth between these two points and therefore P2 can be easily identified as the surge reflected from the fault point. P3 has a corresponding distance of twice the distance from the fault point to point $\mathrm{A}$ and is the surge that is reflected from the fault point for the second time.

For a fault distance of $2.5 \mathrm{~km}$, i.e. between point AA and B, the current waveform is shown in Fig. 4. (Only the faulted phase current waveform is shown).

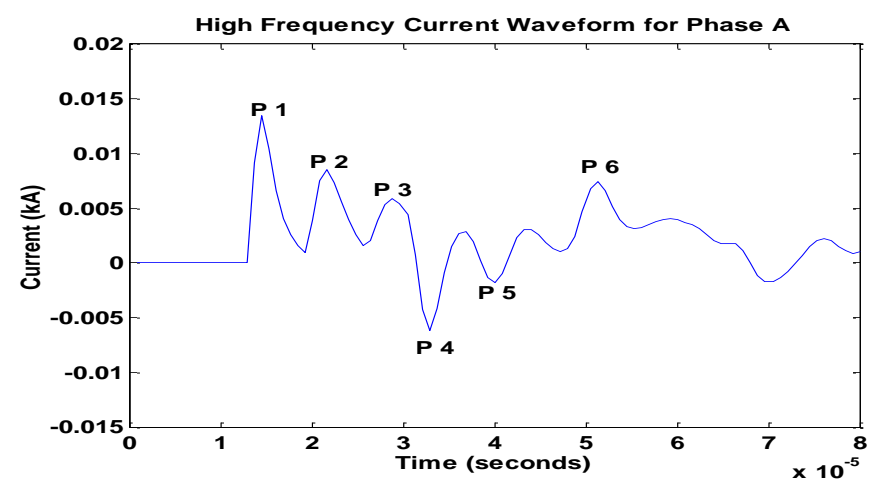

Fig. 4: Phase A current waveform for a fault at a distance of $2.5 \mathrm{~km}$. 
With reference to this waveform, the time delay and the corresponding distances from P1 to each subsequent peak are listed in Table 2 .

Table 2: Calculated distance of each peak relative to P1 for fault at $2.5 \mathrm{~km}$.

\begin{tabular}{ccc}
\hline Peak & Time Delay $(\boldsymbol{\mu}$ seconds) & Distance $(\mathbf{k m})$ \\
\hline P1 & 0.0 & 0 \\
P2 & 7.2 & 1.08 \\
P3 & 14.4 & 2.16 \\
P4 & 18.4 & 2.76 \\
P5 & 25.6 & 3.84 \\
P6 & 36.8 & 5.52 \\
\hline
\end{tabular}

From Fig. 4, there are some peaks (P4 and P5) which are opposite in polarity compared to the incident fault surge, P1. Since the impedance of the cable is much lower than that of the overhead line, a positive incident current wave will be reflected with a negative polarity at a transition point between the cable section and overhead line. Therefore it can be assumed that the fault is located beyond the cable section (point AA). This is confirmed by the calculated distance of peak 4 with respect to P1 which is close to the effective length of the cable. As for P2, the calculated distance is the distance between the fault point and point AA (actual distance is $1.0 \mathrm{~km}$ ). Comparing the calculated distances with the known distances in the network, the following assumptions can be made:

1. P2 might be a surge reflected from L2 since the distance is close to the length of branch CL2 $(1.04 \mathrm{~km})$

2. P4 corresponds to the surge reflected from point AA.

3. P5 might be a surge reflected from L1 since the distance is close to the length of branch BL1 $(3.88 \mathrm{~km})$

From the assumptions, it might seem that the fault could be beyond point $\mathrm{C}$ since there are reflections from L1 and L2. However, analysis on the polarity of the surge suggests that P5 could not be the surge reflected from L1 as the surge reflected from that point is expected to be positive in polarity. Taking that into consideration, the fault is assumed to be located between point $\mathrm{AA}$ and $\mathrm{B}$ and $\mathrm{P} 2$ is the surge reflected from the fault point.

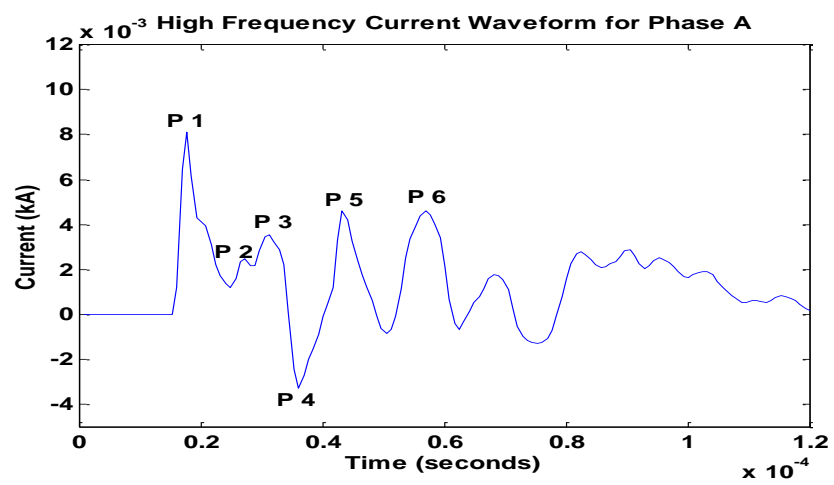

Fig. 5: Phase A current waveform for a fault at a distance of $3.4 \mathrm{~km}$. 
For a fault distance of $3.4 \mathrm{~km}$, i.e. between point B and C, the current waveform is shown in Fig. 5. (Only the faulted phase current waveform is shown)

With reference to the waveform of Fig. 5, the time delay and the corresponding distances from $\mathrm{P} 1$ to each subsequent peak are shown in Table 3.

Table 3: Calculated distance of each peak relative to P1 for fault at $3.4 \mathrm{~km}$.

\begin{tabular}{ccc}
\hline Peak & Time Delay $(\boldsymbol{\mu \text { seconds } )}$ & Distance $(\mathbf{k m})$ \\
\hline P1 & 0.0 & 0 \\
P2 & 9.6 & 1.44 \\
P3 & 13.6 & 2.04 \\
P4 & 18.4 & 2.76 \\
P5 & 25.6 & 3.84 \\
P6 & 39.2 & 5.88 \\
\hline
\end{tabular}

Comparing the calculated distance with the known distances in the network the following conclusions can be made:

1. $\mathrm{P} 2$ corresponds to the surge reflected from point $\mathrm{B}$ (the distance from AA-B is $1.4 \mathrm{~km}$ ).

2. P4 corresponds to the incident surge reflected from the end of the cable.

3. $\mathrm{P} 5$ is the surge reflected from the end of the branch L1 (the distance of branch B-L1 is 3.88 $\mathrm{km})$.

From the above analysis, the location of the fault can be assumed to be beyond point B as there is a surge reflected from the end of the branch L1. Yet, the fault position cannot be beyond point $\mathrm{C}$ as there is no other peak that corresponds to any other length of a branch beyond $\mathrm{C}$. Since the length of the section from point $\mathrm{B}$ and $\mathrm{C}$ is $1.64 \mathrm{~km}$, the estimated fault location is between 2.9 $\mathrm{km}$ and $4.54 \mathrm{~km}$ from $\mathrm{A}$.

For a fault distance of $4.94 \mathrm{~km}$, i.e. between point C and D, the phase A current waveform is shown in Figure 6.

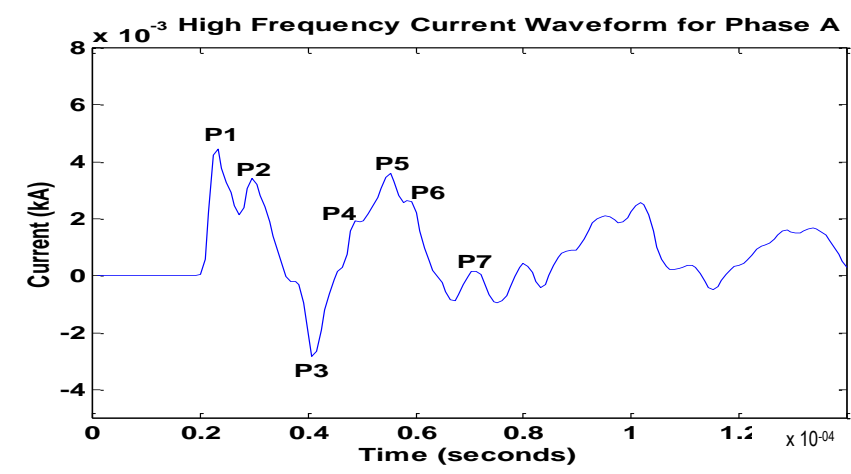

Fig. 6: Phase A current waveform for a fault at a distance of $4.94 \mathrm{~km}$.

The time delay and the corresponding distances from P1 to each subsequent peak are shown in Table 4. 
Table 4: Calculated distance of each peak relative to P1 for fault at $4.94 \mathrm{~km}$.

\begin{tabular}{ccc}
\hline Peak & Time Delay $(\mu$ seconds $)$ & Distance $(\mathbf{k m})$ \\
\hline P1 & 0.0 & 0 \\
P2 & 6.4 & 0.96 \\
P3 & 18.4 & 2.76 \\
P4 & 25.6 & 3.84 \\
P5 & 32.5 & 4.8 \\
P6 & 36.0 & 5.4 \\
P7 & 48.0 & 7.2 \\
\hline
\end{tabular}

Comparing the calculated distance with the known distances in the network the following conclusions can be made:

1. P2 corresponds to the surge reflected from the end of the branch L2 (C-L2 $=1.04 \mathrm{~km})$.

2. $\mathrm{P} 3$ corresponds to the incident surge reflected from the end of the cable.

3. P4 is the surge reflected from the end of the branch L1 $(\mathrm{B}-\mathrm{L} 1=3.88 \mathrm{~km})$.

As there are reflections from $\mathrm{L} 1$ and $\mathrm{L} 2$, the fault location can be identified to be within section C-D, i.e. the location is between $4.54 \mathrm{~km}$ and $5.32 \mathrm{~km}$ from A.

As the fault was moved along the network, the current waveforms become more complex due to multiple reflections from the T points and from the end of the branch; see Figs. 3, 4, and 5 and 6. For Fig. 6, the waveform was obtained when the fault was at a position where there are two branches between the fault and measurement point. To observe the current waveforms for a fault further away from the measurement point, a fault at $10.32 \mathrm{~km}$ (between $\mathrm{E}$ and $\mathrm{F}$ ) was simulated and the current waveform is shown in Fig. 7.

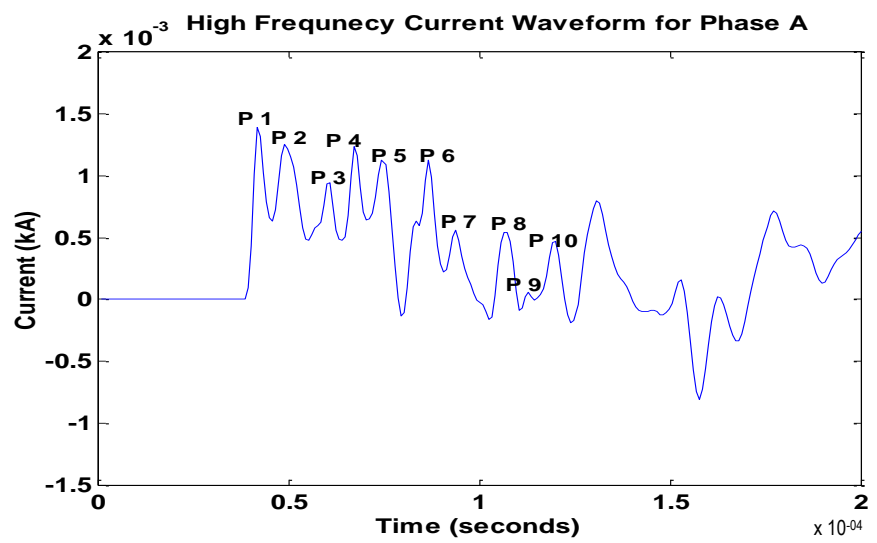

Fig. 7: Phase A current waveform for a fault at a distance of $10.32 \mathrm{~km}$.

The time delay and the corresponding distances from P1 to each subsequent peak are shown in Table 5. 
Table 5: Calculated distance of each peak relative to P1 for fault at $10.32 \mathrm{~km}$.

\begin{tabular}{ccc}
\hline Peak & Time Delay $(\mu$ seconds $)$ & Distance $(\mathbf{k m})$ \\
\hline P1 & 0.0 & 0 \\
P2 & 7.2 & 1.08 \\
P3 & 19.2 & 2.88 \\
P4 & 26.4 & 3.96 \\
P5 & 32.8 & 4.92 \\
P6 & 45.6 & 6.84 \\
P7 & 52.8 & 7.92 \\
P8 & 65.6 & 9.84 \\
P9 & 72.0 & 10.8 \\
P10 & 78.4 & 11.76 \\
\hline
\end{tabular}

The existence of several branches between the fault and the measurement point makes it more difficult to trace the path of the surge corresponding to each peak. However, there are some peaks whose corresponding distances relative to P1 are close to some of the known distances in the network. For instance:

1. P2 corresponds to a distance of $1.08 \mathrm{~km}$, which is close to a known distance of branch C-L2 $(1.04 \mathrm{~km})$.

2. $\mathrm{P} 3$, which corresponds to a distance of $2.88 \mathrm{~km}$, can be assumed to be a surge reflected from either point B (the distance from A to B is $2.9 \mathrm{~km}$ ) or point L4 (the length of branch E-L4 is $2.84 \mathrm{~km}$ ) or a combination of both.

3. P4 is the surge reflected from point L1 as the calculated distance is close to the length of branch B-L1 $(3.88 \mathrm{~km})$.

4. P6 is the surge reflected from L3 as the calculated distance is close to the length of branch D-L3 $(6.74 \mathrm{~km})$.

From the conclusions, the faulty section can be identified as between point $\mathrm{E}$ and $\mathrm{F}$ since there are reflection signals from branch B-L1, C-L2, D-L3 and E-L4. Knowing the faulty section, the distance to the fault can be estimated to be between $7.32 \mathrm{~km}$ to $10.70 \mathrm{~km}$.

\section{CROSS-CORRELATION ANALYSIS}

Since the surge impedance difference between the cable and overhead line is large (at point AA), the reflection factor at this particular point is also large. Therefore, if the fault is located beyond this point, only a small fraction of the incident fault surge reflected from the substation (point A) will return to the fault point. In this case, a fault location estimation based on measuring the time delay between the arrival of the fault incident surge and the surge reflected from the fault will not be correct. However, since the fault section can be identified, faults can be simulated at several positions within the faulted section and the simulated waveforms can be cross-correlated against the original waveform.

Table 6 summarises the conclusions of the five fault location cases discussed in this paper. 
Table 6: Summary of the fault section identification for all five cases.

\begin{tabular}{cccc}
\hline Case & $\begin{array}{c}\text { Actual Fault } \\
\text { Location }\end{array}$ & Identified Fault Section & $\begin{array}{c}\text { Estimated Fault Location } \\
(\mathbf{k m})\end{array}$ \\
\hline 1 & 1.0 & A-AA & $0.00-1.50$ \\
2 & 2.5 & AA-B & $1.50-2.90$ \\
3 & 3.4 & B-C & $2.90-4.54$ \\
4 & 4.94 & C-D & $4.54-5.32$ \\
5 & 10.32 & E-F & $7.32-10.70$ \\
\hline
\end{tabular}

For case 3, the identified fault section is B-C and the fault can be anywhere from $2.90 \mathrm{~km}$ to $4.54 \mathrm{~km}$. Faults were simulated at $3.0 \mathrm{~km}, 3.5 \mathrm{~km}, 4.0 \mathrm{~km}$ and $4.5 \mathrm{~km}$ from A and the waveforms were compared against the original waveform. Figure 8, 9, 10 and 11 show the simulated waveforms at these locations.

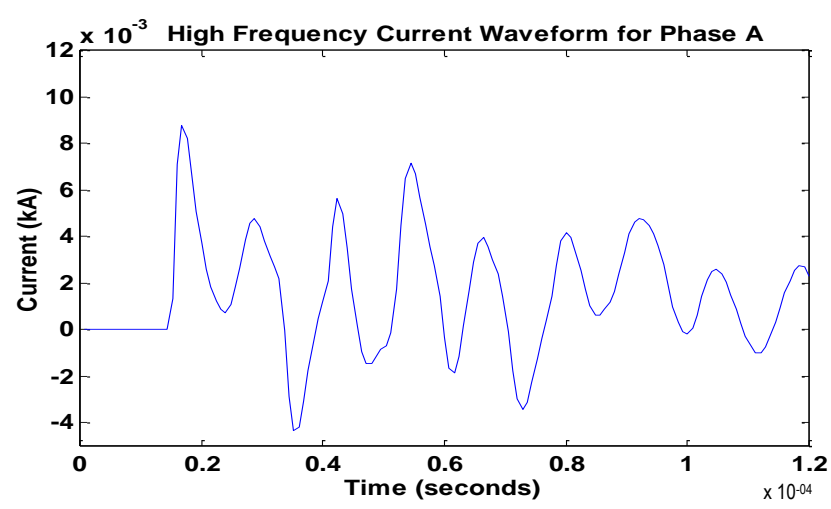

Fig. 8: Fault at $3.0 \mathrm{~km}$.

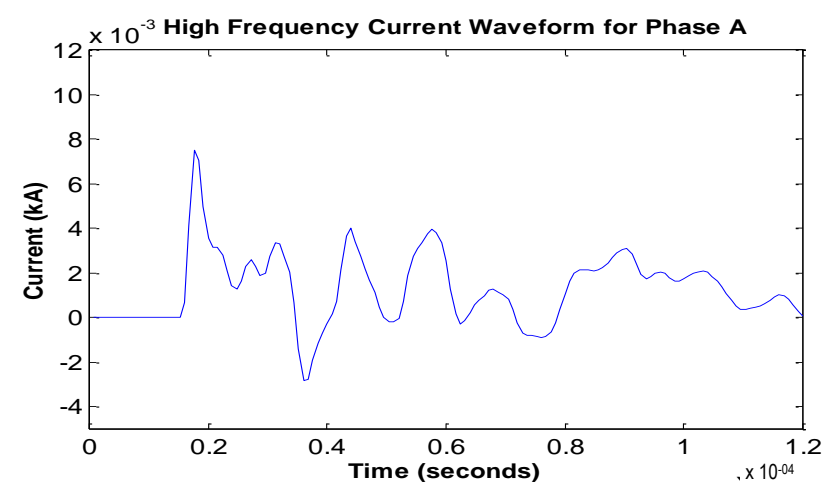

Fig. 9: Fault at $3.5 \mathrm{~km}$.

Visual inspection suggests that the waveform for a fault at $3.5 \mathrm{~km}$ (Figure 9) is the closest match to the actual fault signal, shown in Figure 5. In order to confirm this, a cross-correlation coefficient is calculated and the results are presented in Table 7. 


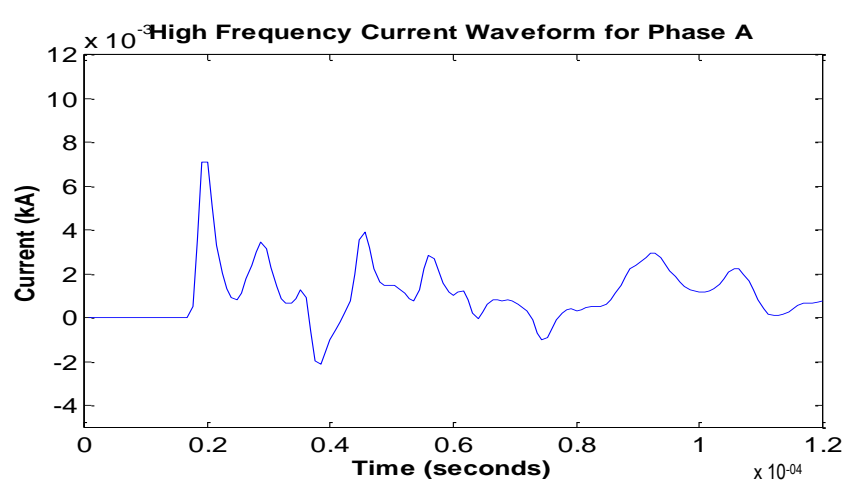

Fig. 10: Fault at $4.0 \mathrm{~km}$.

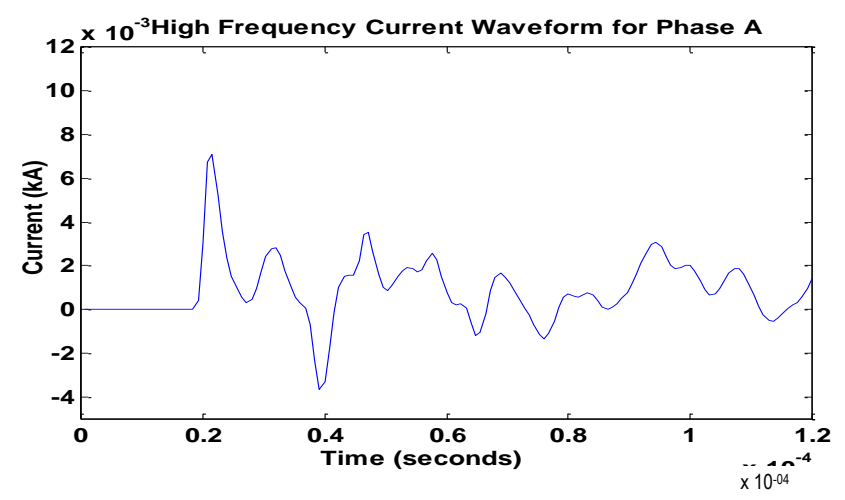

Fig. 11: Fault at $4.5 \mathrm{~km}$.

Table 7: Correlation coefficient for probable fault distances for the fault at $3.4 \mathrm{~km}$.

\begin{tabular}{|c|c|c|c|c|}
\hline \multirow{2}{*}{$\begin{array}{l}\text { Fault distance } \\
\qquad(\mathbf{k m})\end{array}$} & \multicolumn{3}{|c|}{ Cross-Correlation Window } & \multirow[t]{2}{*}{ Average $(\mathrm{CC})$} \\
\hline & \multicolumn{3}{|c|}{ Correlation Coefficient (CC) } & \\
\hline \multirow{2}{*}{3.0} & 50 & 75 & 100 & \multirow{2}{*}{0.9339} \\
\hline & 0.9526 & 0.9309 & 0.9182 & \\
\hline \multirow{2}{*}{3.5} & 50 & 75 & 100 & \multirow{2}{*}{0.9715} \\
\hline & 0.9705 & 0.9718 & 0.9722 & \\
\hline \multirow{2}{*}{4.0} & 50 & 75 & 100 & \multirow{2}{*}{0.8235} \\
\hline & 0.8501 & 0.8180 & 0.8025 & \\
\hline \multirow{2}{*}{4.5} & 50 & 75 & 100 & \multirow{2}{*}{0.7564} \\
\hline & 0.8092 & 0.7491 & 0.7109 & \\
\hline
\end{tabular}

The above results confirm that the waveform for fault at $3.5 \mathrm{~km}$ is the closest match to the waveform of the original fault which was located at $3.4 \mathrm{~km}$. 


\section{CONCLUSIONS}

This paper has presented a method based on high frequency travelling waves generated by the faults for fault location. The study based on simulations suggests that by calculating the relative distance of the "peak" in the high frequency travelling waves and comparing it with the known distance in the distribution feeder, it is possible to identify the faulty section and the probable location of the fault. Additional research efforts will be undertaken to take into account other power system configurations and the effect of fault resistances to the waveforms generated.

\section{REFERENCES}

1. Glover, J.D. and Sarma, M. (2001), Power System Analysis \& Design, ThomsonEngineering, U.S.A., 3rd Edition.

2. Crossley, P.A. and MacLaren, P.G. (1983), Distance protection based on travelling waves, IEEE Transactions on Power Apparatus and System, vol. PAS 102, No. 9, pp. 2971-2983.

3. Ancell, G.B. and Pahalawaththa, N.C. (1994), Maximum likelihood estimation of fault location on transmission lines using travelling waves, IEEE Transactions on Power Delivery, Vol. 9, No. 2, pp. 680-689.

4. Jie Liang, Elangovan, S., and Devotta, J.B.X. (1999), Adaptive travelling wave protection algorithm using two correlation functions, IEEE Transactions on Power Delivery, Vol. 14, No.1, pp. 126-131.

5. Bo, Z.Q., Weller, G., and Redfern, M.A. (1999), Accurate fault location technique for distribution system using fault-generated high-frequency transient voltage signals, IEE Proceedings - Generation, Transmission and Distribution, Volume 146, Issue 1, , pp. 73 79.

6. Crossley, P.A., Gale, P.F., and Aurangzeb, M. (2001), Fault location using high frequency travelling waves measured at a single location on a transmission line, Developments in Power System Protection, Amsterdam, Holland, 9-12 April 2001, pp. 403-406.

7. Elhaffar, A. and Lehtonen, M. (2004), Travelling waves based earth fault location in $400 \mathrm{kV}$ transmission network using single end measurement, Large Engineering systems Conference on Power Engineering, LESCOPE-04, 28-30 July 2004, pp. 53-56.

8. Thomas, D.W.P., Christopoulos, C., Tang, Y., Gale, P., and Stokoe, J. (2004), Single ended travelling wave fault location scheme based on wavelet analysis, Eighth IEE International Conference on Developments in Power System Protection, Volume 1, 5-8 April 2004, pp. 196-199.

9. Zeng Xiangjun, Li, K.K., Liu Zhengyi, and Yin Xianggen (2004), Fault location using traveling wave for power networks, Industry Applications Conference, 2004, 39th IAS Annual Meeting, 3-7 Oct. 2004, Vol. 4, pp. 2426-2429.

10. Evrenosoglu, C.Y. and Abur, A. (2005), Travelling wave based fault location for teed circuits, IEEE Transactions on Power Delivery, Volume 20, Issue 2, Part 1, April 2005 pp. $1115-1121$.

11. Gale, P.F. and Giannattasio, B.F. (1994), Travelling waves get to the point, Modern Power Systems, pp. 45-47.

12. Bewley, L.V. (1951), Travelling waves on transmission systems, John Wiley \& Sons Inc., New York. 